\title{
A Study on Postpartum Hypertension in A Tertiary Care Centre.
}

\author{
Dr.R.Manonmani,MD.DGO ${ }^{1}$, Dr.A.Devi Lakshmi,MD(OG) ${ }^{2}$ \\ ${ }^{1}$ Associate Professor, Coimbatore Medical College Hospital \\ ${ }^{2}$ Assistant Professor,Coimbatore Medical College Hospital
}

Background: Postpartum blood pressure (BP) is highest three to six days after birth when most women have been discharged home. A significant rise in BP may be dangerous (e.g., lead to stroke), but there is little information about how to prevent or treat postpartum hypertension.

\begin{abstract}
Aims And Objectives
To analyse the trends of blood pressure in the postnatal period in patients with hypertensive disorders of pregnancy. To emphasise the significance of vigilant monitoring of blood pressure in the postpartum period atleast for 6 weeks.
\end{abstract}

Place And Period Of Study

At Coimbatore medical college hospital for a period of three months from July to September 2016.

\section{Materials And Methods}

A prospective study involving around 100 inpatients of hypertensive disorders of pregnancy who delivered in our hospital were included in our study. Strict vigilant monitoring of blood pressure every 6 hours was done for these patients and were documented for fourteen days postpartum.

\section{Review Of Literature}

Hypertensive disorders of pregnancy are a major cause of maternal mortality and morbidity, especially in developing countries. ${ }^{1}$ Hypertension may be present before or during pregnancy or postpartum. ${ }^{2}$ Postpartum hypertension can be related to persistence of gestational hypertension $(\mathrm{GH})$, preeclampsia, or preexisting chronic hypertension, or it could develop de novo secondary to other causes and continue to pose a risk to maternal well-being. These risks are magnified as many patients present after hospital discharge and go unrecognized because of decreased medical surveillance after delivery.

\section{Incidence}

Research studies dealing with postpartum hypertension are usually limited by analysis of data from a single center, focused on inpatients in the immediate postpartum period (2-6 days), or describing patients who were readmitted because of preeclampsia-eclampsia,severe hypertension, or complications related to hypertension. ${ }^{12-17}$ Despite the limitations, the reported prevalence of de novo postpartum hypertension or preeclampsia ranges from 0.3 to $27 \%$.

\section{Etiology And Differential Diagnosis}

The etiology and different diagnosis of postpartum hypertension is extensive, but it can be focused based on clinical and laboratory findings as well as response to treatment of BP. GHT-preeclampsia(new onset or preexisting prior to delivery) is the most common cause, however, other life-threatening conditions such as pheochromocytoma and cerebrovascular accidents should also be considered..

\section{New Onset Pospartum Hypertension And Preeclampsia}

Normal pregnancy is characterized by increased plasma volume in association with sodium and water retention in the interstitial tissue. This is further aggerated in women with multifetal gestation. In addition, many women receive intravenously a large volume of fluids during labor, delivery, and postpartum. Large volumes of fluids are also given because of regional analgesia-anesthesia or during cesarean section. In some women, acute or delayed mobilization of large volume of fluid into the intravascular space, particularly in association with suboptimal renal function, can lead to a state of volume overload resulting in hypertension.

In women with preeclampsia,there is a decrease in BP within 48 hours, but BP increases again between 3-6 days postpartum. ${ }^{20}$ In some patients,cerebral manifestations and/or deterioration in maternal laboratory findings will manifest for the first time postpartum leading to the development of eclampsia or HELLP syndrome. 


\section{Complications}

The potential complications of postpartum hypertension are serious and can be lifethreatening and include eclampsia,stroke,congestive heart failure,renal failure and permanent disability..this risk may persist for 4 weeks postpartum. Therefore emphasis has shifted to continue close monitoring of patients for a longer period of time.,as well as patient and provider education regarding the signs and symptoms of postpartum hypertension and preeclampsia.

\section{Current Recommendations}

Recommendations take into account that blood pressure that initially decreases after delivery may increase 3 to 6 days postpartum in patiens with preeclampsia. The current hypertension guidelines suggest blood pressure monitoring for for 72 hours postpartum and then again 7 to 10 days postpartum as well.patients should be evaluated for other causes of hypertension (eg,thyroid disease , adrenal disease, cardiomyopathy ,lupus, hemolytic uremic syndrome).patients with persistent postpartum hypertension beyond 24 hours should have any medications that could be exacerbating blood pressure. (eg.vasoconstrictive medications, NSAIDS) discontinued.Patients with signs and symptoms with preeclampsia or HELLP syndrome should be treated with magnesium prophylaxis for 24 hours. Antihypertensives must be started for 150/100 mm of $\mathrm{Hg}$..

IV. Tables And Discussion

Table 1

\begin{tabular}{|l|l|}
\hline Age Of Presentation & $\begin{array}{l}\text { No.Of Patients With Hypertensive } \\
\text { Disorders. }\end{array}$ \\
\hline$<20$ & 28 \\
\hline $21-30$ & 60 \\
\hline $31-35$ & 10 \\
\hline$>36$ & 2 \\
\hline & \\
\hline
\end{tabular}

In our study, we found that $60 \%$ of hypertensive patients were found in the age group of 21 to 30 years.

Table 2

\begin{tabular}{|l|l|l|l|l|}
\hline Age & Ght & Pet & Sev Pet & Ecl \\
\hline$<20$ & 7 & 4 & 14 & 3 \\
\hline $\begin{array}{l}21- \\
30\end{array}$ & 27 & 6 & 24 & 3 \\
\hline $\begin{array}{l}31- \\
35\end{array}$ & 4 & & 6 & - \\
\hline$>36$ & - & & 6 & - \\
\hline & & 1 & 1 & \\
\hline
\end{tabular}

The incidence of preeclampsia and postpartum hypertension were higher in the age group of 21-30 years.

Table 3 Gestational Age At First Diagnosis

\begin{tabular}{|l|l|l|}
\hline $\begin{array}{l}\text { Gestational Age At } \\
\text { Presentation }\end{array}$ & Gestational Hypertension & $\begin{array}{l}\text { Severe } \\
\text { Preeclampsia }\end{array}$ \\
\hline 24-28 Weeks & 2 & 3 \\
\hline 28-32 Weeks & 12 & 14 \\
\hline 32-36weeks & 14 & 23 \\
\hline$>36$ weeks & 18 & 14 \\
\hline
\end{tabular}

The incidence of preeclampsia was higher at the gestational age of more than 32 weeks. This may be due to the increased frequency of AN visits beyond this gestational age.

Table 4 Mode Of Delivery

\begin{tabular}{|l|l|l|}
\hline & LSCS & NVD \\
\hline Gestational Hypertension & 21 & 19 \\
\hline Severe Preeclampsia & 20 & 9 \\
\hline Imminent Eclampsia & 15 & 13 \\
\hline Eclampsia & 2 & 1 \\
\hline
\end{tabular}

The outcome and mode of delivery in these patients were analysed and it was found that around 58\% of patients ended up in Caeserean sections..

Table 5 Postpartum Hypertension

\begin{tabular}{|l|l|l|}
\hline Blood Pressure & Day 3 & Day 10 \\
\hline$<140 / 90$ & 55 & 69 \\
\hline $140 / 90-160 / 100$ & 33 & 28 \\
\hline$>160 / 100$ & 12 & 03 \\
\hline
\end{tabular}


Postdelivery,the blood pressure values were vigilantly monitored and documented for 14days. On analysis we found that there was a significant $(\mathbf{5 5 \%})$ fall in blood pressure values on the third day.(ie after 48-72 hrs of delivery). But on keen observation we found that by day 10 ,only $69 \%$ of patients had normal bloodpressure .remaining $31 \%$ still had high BP values, warranting the significance of continuing antihypertensive medications. Adding to this fact,among those 55 patients who had a fall in BP on the $3^{\mathrm{rd}}$ day,nine patients $(16.3 \%$ ) had a sudden rise in blood pressure on day 9 and day 10 which implies the importance of postpartum BP monitoring.

Table 6

\begin{tabular}{|l|l|l|l|l|}
\hline & \multicolumn{2}{|c|}{ DAY 3 } & \multicolumn{2}{c|}{ DAY 10 } \\
\hline & $<140 / 90$ & $>140 / 90$ & $<140 / 90$ & $>140 / 90$ \\
\hline Ght & 32 & 3 & 30 & 5 \\
\hline Preecl & 6 & 5 & 7 & 4 \\
\hline Sev Pet/Ecl & 17 & 37 & 32 & 22 \\
\hline & 55 & 45 & 69 & 31 \\
\hline
\end{tabular}

From this table,we infer that in severe preeclampsia patients,even on day 10 ,nearly $22 \%$ still recorded high BP values..This implies that BP monitoring has to be continued even after discharge for 6 weeks postpartum.

Table 7

\begin{tabular}{|l|l|l|l|}
\hline & \multicolumn{3}{|l|}{ Postpartum Hypertension >140/90 } \\
\hline $\begin{array}{l}\text { Diagnosis-Termination } \\
\text { Interval }\end{array}$ & Day 3 & Day 10 & $\begin{array}{l}\text { Ht } \\
\text { Percent }\end{array}$ \\
\hline$>4$ Weeks & 20 & 16 & $80 \%$ \\
\hline$<4$ Weeks & 17 & 13 & $76 \%$ \\
\hline Immediate & 8 & 2 & $25 \%$ \\
\hline & 45 & 31 & \\
\hline
\end{tabular}

From this table,we interpret that the longer the exposure to the pathology in the antenatal period , the higher the incidence of postpartum hypertension.

Table 8 Induction Delivery Interval Vaginal Delivery

\begin{tabular}{|l|l|l|l|l|l|}
\hline Nvd & \multicolumn{5}{|l|}{ Postpartum Hypertension $>\mathbf{1 4 0 / 9 0}$} \\
\hline & & Day 3 & \% & Day10 & Percent \\
\hline$>12 \mathrm{Hrs}$ & 16 & 13 & 81 & 10 & 62 \\
\hline $6-12 \mathrm{Hrs}$ & 15 & 12 & 80 & 6 & 40 \\
\hline$<6 \mathrm{Hrs}$ & 11 & 5 & 45 & 1 & 9 \\
\hline & & 30 & & 17 & \\
\hline
\end{tabular}

We also found that the induction - delivery interval was inversely proportional to the persistence of postpartum hypertension..

\section{Table 9}

Elective lscs-16

Emergencylscs-42

\begin{tabular}{|l|l|l|l|l|l|}
\hline \multicolumn{1}{|c|}{ Em.Lscs } & \multicolumn{5}{|c|}{ Postpartum Hypertension >140/90 } \\
\hline Ind-Lscs Int & & Day 3 & & Day 10 & \\
\hline $0 \mathrm{Hrs}$ & 16 & 7 & $43 \%$ & 2 & $12.5 \%$ \\
\hline$<6 \mathrm{hrs}$ & 17 & 12 & $70 \%$ & 5 & $29 \%$ \\
\hline$>6 \mathrm{Hrs}$ & 9 & 8 & $88 \%$ & 7 & $77 \%$ \\
\hline & & & & & \\
\hline
\end{tabular}

Similarly when the induction-LSCS interval is $>6$ hours, there was only $10 \%$ reduction in blood pressure by the $10^{\text {th }}$ day.

\section{Conclusion}

From our study,we found that even on $10^{\text {th }}$ day,many of the patients had elevated blood pressure inspite of a decreasing trend on the $3^{\text {rd }}$ day. Thus, we infer that routine antihypertensive therapy must be continued for all patients with preeclampsia atleast for 4 weeks postpartum. We also found that induction-delivery interval and diagnosis-termination interval were inversely proportional to the rate of fall in blood pressure. Hence,sooner the termination of pregnancy,better the prognosis in the postpartum period. Since many cases of postpartum hypertension are due to "residual" preeclampsia or the effect of volume and or NSAID therapy, reevaluation of patients in 2 to 4 weeks of hospital discharge is quite reasonable. 
During this immediate postdischarge period, we also advocate regularly measured home or self-BP measurement as an important step to follow any transitions in BP that might occur in women with postpartum hypertension.

\section{Summary}

In summary, there are several causes for postpartum hypertension; some may be benign (mild GH or mild chronic hypertension)whereas others can be lifethreatening such as severe preeclampsia or stroke. Therefore, a high index of suspicion for secondary dangerous causes of hypertension should be considered when evaluating such women. By directing efforts and educating health care providers about the continued monitoring,reporting, and prompt evaluation of symptoms in the postpartum period, it is expected that some of the maternal complications will be avoided.

Evaluation and management of women with postpartum hypertension should be guided by obtaining a detailed history, careful physical examination, selective laboratory and imaging studies, and response to initial treatment. Until now, the focus of pregnancy-associated hypertension research has been on antepartum hypertension,with only a few studies and reviews addressing the postpartum period. There is no doubt that antepartum hypertension is a high-risk situation, and that delivery of a healthy, live baby is of utmost importance. Fortunately, maternal catastrophies such as death, stroke, and seizures are rare, but there is mounting evidence that the incidence of postpartum thrombotic and hemorrhagic strokes is increasing just as maternal hypertension is rising.

\section{References}

[1]. Goldenberg RL, McClue EM, MacGuire ER,Kamath BD, Jobe AH. Lessons for low-income regions following the reduction in hypertensionrelated maternal mortality in high-income countries. Int J Gynecol Obstet 2011;113:91-5.

[2]. Sibai BM. Diagnosis and management ofgestational hypertension and preeclampsia. Obstet Gynecol 2003;102:181-92.

[3]. Tan L, de Swiet M. The management of postpartum hypertension. BJOG 2002; 109:733-6.

[4]. Report of the national high blood pressure education program working group on high blood pressure in pregnancy. Am $\mathrm{J}$ Obstet Gynecol 2000;183:S1-22.

[5]. American College of Obstetricians and Gynecologists.ACOG practice bulletin no. 33: diagnosis and management of preeclampsia and eclampsia. Washington, DC: The College; 2002.

[6]. Sibai BM. Diagnosis and management of HELLP syndrome. Obstet Gynecol 2004;105:

[7]. 7.Kuklina EV, Tong X, Bansil P, George MG, Callaghan WM. Trends in pregnancy hospitalizations that included a stroke in the United States from 1994 to 2007: reasons for concern? Stroke. 2011;42:2564-2570. doi:10.1161/STROKEAHA.110.610592.

[8]. Goel A, Maski MR, Bajracharya S, Wenger JB, Zhang D, Salahuddin S, Shahul SS, Thadhani R, Seely EW, Karumanchi SA, Rana S. Epidemiology and mechanisms of de novo and persistent hypertension in the postpartum period. Circulation. 2015;132:17261733. doi: 10.1161/CIRCULATIONAHA.115.015721.

[9]. Magee L, von Dadelszen P. Prevention and treatment of postpartum hypertension. Cochrane Database Syst Rev. 2013;4:CD004351. doi: 1002/14651858.CD004351.pub3

[10]. Wasden SW, Ragsdale ES, Chasen ST, Skupski DW. Impact of nonsteroidal anti-inflammatory drugs on hypertensive disorders of pregnancy.Pregnancy Hypertens. 2014;4:259-263. doi: 10.1016/j. preghy.2014.06.001.

[11]. Johnson AG, Nguyen TV, Day RO. Do nonsteroidal anti-inflammatory drugs affect blood pressure? A meta-analysis. Ann Intern Med.1994;121:289-300

[12]. Makris A, Thornton C, Hennessy A. Postpartum hypertension and nonsteroidal analgesia. Am J Obstet Gynecol. 2004;190:577578. doi: 10.1016/j.ajog.2003.08.030.

[13]. Ojogwu LI, Ofili UG. Morbidity and mortality from postpartum hypertension in Nigerian women. Afr J Med Med

[14]. Sci. 1993;22:11-16.

[15]. Matthys LA, Coppage KH, Lambers DS, et al. Delayed postpartum preeclampsia: an experience of 151 cases. Am J Obstet Gynecol.2004;190:1464-1466.

[16]. Yancey LM, Withers E, Bakes K, et al. Postpartum preeclampsia: emergency department presentation and management.

[17]. J Emerg Med. 2008 Sep 22. 